\title{
Effect of Additional Element on Hydrogen Absorption for Iron in Acidic and Neutral Sulfate Solutions
}

\author{
Takumi HARUNA, ${ }^{1) *}$ Kazuki TAKEUCHI, ${ }^{2)}$ Tomoki KASAHARA ${ }^{2)}$ and Yamato NII ${ }^{3)}$
}

1) Faculty of Chemistry, Materials and Bioengineering, Kansai University, 3-3-35 Yamatecho, Suita, Osaka, 564-8680 Japan. 2) Undergraduate Student in Faculty of Chemistry, Materials and Bioengineering, Kansai University, 3-3-35 Yamatecho, Suita, Osaka 564-8680 Japan. 3) Graduate Student in Graduate School of Science and Engineering, Kansai University, 3-3-35 Yamatecho, Suita, Osaka, 564-8680 Japan.

(Received on May 1, 2015; accepted on May 15, 2015; J-STAGE Advance published date: February 4, 2016)

\begin{abstract}
Effects of additional elements of $\mathrm{Cr}$ and $\mathrm{Ni}$ in iron on hydrogen absorption behavior have been investigated by means of conventional electrochemical hydrogen permeation test. Empirical transient curve of hydrogen permeation current density was agreed with theoretical one on the basis of Fick's second law with a fixed hydrogen concentration at the hydrogen absorption surface, $C_{0}$, at any time. The fact suggests quasi-equilibrium condition to the absorption-desorption reaction of hydrogen at the surface, and that correlation between $C_{0}$ and hydrogen absorption rate. As an analytical result of the transient, a diffusion coefficient decreased with an increase in a content of additional elements, and the decrement was enhanced much more by $\mathrm{Cr}$ than by $\mathrm{Ni}$. $\mathrm{C}_{0}$ was almost proportional to a square root of the cathodic current density at the hydrogen absorption surface for any specimens. The slope increased with an increase in a content of the additional elements, and the increment was enhanced much more by $\mathrm{Cr}$ than by Ni. There was a correlation between the slope and the diffusion coefficient, and the correlation suggested that the additional elements of $\mathrm{Cr}$ and $\mathrm{Ni}$ attract hydrogen. In addition, the attraction effect of $\mathrm{Cr}$ was much more than that of $\mathrm{Ni}$. Under anodic potential region, the effect of additional element on $C_{0}$ was not clearly obtained in the solution of $\mathrm{pH} 2$, but it is found that $C_{0}$ of the $\mathrm{Cr}$-added steel was larger and that of the $\mathrm{Ni}$-added steel was smaller than that of $\mathrm{Fe}$ in the solution of $\mathrm{pH} 6$.
\end{abstract}

KEY WORDS: hydrogen embrittlement; iron; additional element; hydrogen absorption rate; diffusion coefficient of hydrogen; hydrogen permeation test.

\section{Introduction}

High strength steels have been desired from the viewpoints of energy-saving, material-saving, environment conservation, safety of structures, and so on. However, it is well known that the steels with higher strength suffer hydrogen embrittlement (HE) when corrosion takes place to the steels employed in humid conditions. ${ }^{1)}$ The phenomena have been recognized for more than many years, and a lot of researches have been conducted to understand the mechanism and to propose the methods for protection to HE. ${ }^{2-4)}$ Most of the researches have focused on the control of microstructure of the steel $^{5)}$ and on the comprehension of diffusion kinetics of hydrogen in the steel. ${ }^{6}$ However, quite few approaches to prevent HE were conducted from absorption reaction of hydrogen into the steel. Understanding of hydrogen absorption process is also very important to suppress susceptibility of HE, and leads to possibility of discover the 'hydrogenpassive' surface that prevents hydrogen absorption into the steel to avoid HE without any microstructural control. From the point of view, The Iron and Steel Institute of Japan

\footnotetext{
* Corresponding author: E-mail: haruna@kansai-u.ac.jp DOI: http://dx.doi.org/10.2355/isijinternational.ISIJINT-2015-223
}

has established the study group named 'Comprehensive Understanding of Hydrogen-Passive Surface on Steels for Prevention of Hydrogen Embrittlement' since 2013. ${ }^{7-10)}$ Our research has been conducted in the study group, and tried to understand the role of additional elements in the steel to hydrogen absorption reaction rate. The present research aimed to recognize the effects of additional elements of $\mathrm{Cr}$ and $\mathrm{Ni}$ and their content in $\mathrm{Fe}$ on hydrogen absorption reaction rate by means of conventional hydrogen permeation test.

\section{Experimental}

\subsection{Specimen}

Materials used in this research were $\mathrm{Fe}, \mathrm{Fe}-1 \mathrm{Cr}, \mathrm{Fe}-3 \mathrm{Cr}$, $\mathrm{Fe}-1 \mathrm{Ni}$ and $\mathrm{Fe}-3 \mathrm{Ni}$ (numerical: mass\%). Their chemical compositions were summarized in Table 1. The material sheets were cut into $40 \mathrm{~mm} \times 40 \mathrm{~mm}$ for specimens subjected to a conventional hydrogen permeation test. The surface of the specimen was then mechanically polished by emery papers to $\# 6 / 0$ (corresponding to \#1200).

In order to remove deformed layer on the specimen surface introduced by machining and grinding, electrolytic polishing was conducted to the specimen. $\mathrm{H}_{3} \mathrm{PO}_{4}$ (concen- 
Table 1. Chemical compositions of the steel (mass\%).

\begin{tabular}{cccccccccc}
\hline Specimen & $\mathrm{C}$ & $\mathrm{Si}$ & $\mathrm{Mn}$ & $\mathrm{Cu}$ & $\mathbf{N i}$ & $\mathbf{C r}$ & $\mathrm{Al}$ & $\mathrm{Ti}$ & $\mathrm{V}$ \\
\hline $\mathrm{Fe}-1 \mathrm{Ni}$ & 0.001 & $<0.003$ & 0.01 & $<0.01$ & $\mathbf{0 . 9 8}$ & $<0.01$ & $<0.01$ & $<0.01$ & $<0.01$ \\
$\mathrm{Fe}-3 \mathrm{Ni}$ & 0.001 & $<0.003$ & 0.01 & $<0.01$ & $\mathbf{3 . 0 2}$ & $<0.01$ & $<0.01$ & $<0.01$ & $<0.01$ \\
$\mathrm{Fe}-1 \mathrm{Cr}$ & 0.005 & $<0.003$ & 0.07 & $<0.01$ & $<0.01$ & $\mathbf{1 . 0 1}$ & $<0.01$ & $<0.01$ & $<0.01$ \\
$\mathrm{Fe}-3 \mathrm{Cr}$ & 0.006 & $<0.003$ & 0.05 & $<0.01$ & $<0.01$ & $\mathbf{3 . 0 5}$ & $<0.01$ & $<0.01$ & $<0.01$ \\
\hline
\end{tabular}

tration: 85 mass\%) and $\mathrm{H}_{2} \mathrm{SO}_{4}$ (concentration: 95 mass\%) were mixed by 75 and $25 \mathrm{vol} \%$, respectively, to prepare the polishing solution. Conditions of the electrolytic polishing were as follows; a solution temperature is $298 \mathrm{~K}$, an applied potential is $1.5 \mathrm{~V} \mathrm{Ag} / \mathrm{AgCl}$ and a polishing time is $84.6 \mathrm{ks}$. After the polishing, the specimen surface was removed by about $50 \mu \mathrm{m}$. A thickness of the specimen was accurately measured by a micrometer.

Electrolytic plating of $\mathrm{Ni}$ was then conducted to the specimen as described below. Watt bath $\left(\mathrm{NiSO}_{4} \cdot 6 \mathrm{H}_{2} \mathrm{O}: 250\right.$ $\left.\mathrm{kg} \cdot \mathrm{m}^{-3}, \mathrm{NiCl} \cdot 6 \mathrm{H}_{2} \mathrm{O}: 45 \mathrm{~kg} \cdot \mathrm{m}^{-3}, \mathrm{H}_{3} \mathrm{BO}_{3}: 40 \mathrm{~kg} \cdot \mathrm{m}^{-3}\right)$ at 333 $\mathrm{K}$ was employed for the plating. One side of the specimen surface was fully covered with a polytetrafluoroethylene tape, and a current density of $10 \mathrm{~A} \cdot \mathrm{m}^{-2}$ was applied to the specimen for $420 \mathrm{~s}$ in the bath. Thereafter, Ni layer of about $15 \mathrm{~nm}$ thick was deposited on the specimen after the report by Yoshizawa et al. ${ }^{11)}$

\subsection{Electrochemical Hydrogen Permeation Test}

In the hydrogen permeation test, a Devanathan-Stachursky type cell ${ }^{12)}$ was employed. Schematic illustration of the cell is shown in Fig. 1. The specimen was set between two cells. The cell contacting to the bare iron surface was the hydrogen absorption cell, in which an acidic or a neutral solutions was introduced. The acidic solution was $\mathrm{H}_{2} \mathrm{SO}_{4}$ aqueous solution of $\mathrm{pH} 2$, and the neutral solution was 0.01 $\mathrm{kmol} \cdot \mathrm{m}^{-3} \mathrm{Na}_{2} \mathrm{SO}_{4}$ aqueous solution of about $\mathrm{pH}$ 6. The other cell contacting to the Ni-plated iron surface was the hydrogen detection cell, in which a $0.1 \mathrm{kmol} \cdot \mathrm{m}^{-3} \mathrm{NaOH}$ solution was introduced. All of the solutions were deaerated by $\mathrm{N}_{2}$ gas before $1.8 \mathrm{ks}$ and during the test. In each cell, an $\mathrm{Ag} / \mathrm{AgCl}$ reference electrode and a Pt counter electrode was equipped, and a dual potentiostat (PS-12, Toho Tech. Res. Co.) was connected to them.

Procedure of the test was described as follows: The specimen was set between the two cells, and the $\mathrm{NaOH}$ solution was introduced to the hydrogen detection cell. After the solution was deaerated for $1.8 \mathrm{ks}$, a passivation potential of $0 \mathrm{~V}_{\mathrm{Ag} / \mathrm{AgCl}}$ was applied to the Ni-plated surface. A passivation current density reached $0.2 \mathrm{~mA} \cdot \mathrm{m}^{-2}$, and then the acidic or the neutral solution was introduced to the hydrogen absorption cell. After a corrosion potential of the hydrogen absorption surface and a current density of the Ni-plated specimen surface were stable, the hydrogen permeation test started by applying a given potential to the hydrogen absorption surface. A hydrogen permeation current density, $i_{\mathrm{H}}$, was calculated by a hydrogen detection current density subtracted by a steady passivation current density of Niplated surface.

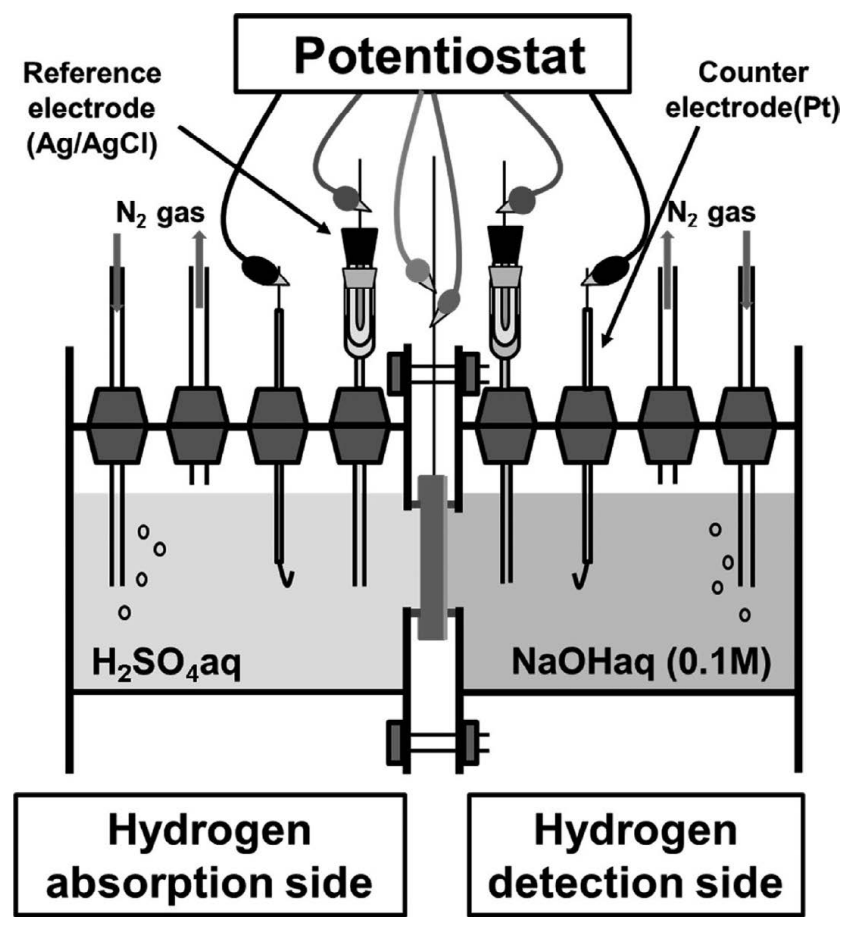

Fig. 1. Schematic illustration of the apparatus for electrochemical hydrogen permeation test.

\subsection{Analysis of the Hydrogen Permeation Current Density}

The change in $i_{\mathrm{H}}$ with the permeation time was analyzed to obtain a diffusion coefficient of hydrogen, $D$, in the steel and a hydrogen concentration of the surface at hydrogen absorption side, $C_{0}$. The empirical $i_{\mathrm{H}}$ transient fitted to the theoretical curve on the basis of Fick's second law in the one-dimension mode,

$$
\mathrm{d} C / \mathrm{d} t=D \mathrm{~d}^{2} C / \mathrm{d} x^{2}
$$

with the following initial and boundary conditions expressed by Eqs. (2) and (3), respectively,

Initial condition: $t=0, C(x=0)=C_{0}, C(0<x \leq L)=0$

Boundary condition: $t>0, C(x=0)=C_{0}, C(x=L)=0$

where $C$ is a concentration of hydrogen at a given time and a given depth of the steel, $t$ is a hydrogen permeation time, $x$ is a depth from the hydrogen absorption surface, and $L$ is the thickness of the steel. From the equations, $D$ was obtained,

$$
D=0.171 L^{2} / t_{0.63}
$$

where $t_{0.63}$ is the time when $i_{\mathrm{H}}$ reaches $63 \%$ to the steady 
state value of the current density, $i_{\mathrm{H}}(t=\infty)$. On the other hand, $C_{0}$ was obtained by $i_{\mathrm{H}}(t=\infty)$ and $D$ on the basis of Fick's first law under the steady state condition of the hydrogen permeation,

$$
C_{0}=i_{\mathrm{H}}(t=\infty) L /(F D)
$$

where $F$ is Faraday's constant.

\section{Results}

\subsection{Diffusion Coefficients of Hydrogen in the Steels}

Since the $i_{\mathrm{H}}$ transient in the permeation test fitted to the theoretical curve on the basis of Fick's second law, values of $D$ in the five materials were obtained by Eq. (4). The value of $D$ for each specimen was obtained by applying a few of cathodic potentials to the hydrogen absorption surface, and an average value was calculated. These coefficients were plotted against a content of $\mathrm{Ni}$ and $\mathrm{Cr}$, and shown in Fig. 2. In addition, the data obtained by the other researchers ${ }^{13-15)}$ were plotted in the figure. The figure indicated that the present values were almost involved in the line of the data obtained by the other researchers, and then confirmed that the present transient of $i_{\mathrm{H}}$ was validly measured. Moreover, it was found that $D$ decreased with an increase in a content of each additional element, and the decrement of $D$ was enhanced more by $\mathrm{Cr}$ than by $\mathrm{Ni}$.

3.2. Effect of $C_{0}$ on the Potential Applied to the Hydrogen Absorption Surface

\subsubsection{Cathodic Potential Region}

From the hydrogen permeation test, polarization curves for the hydrogen absorption surface were obtained, and the

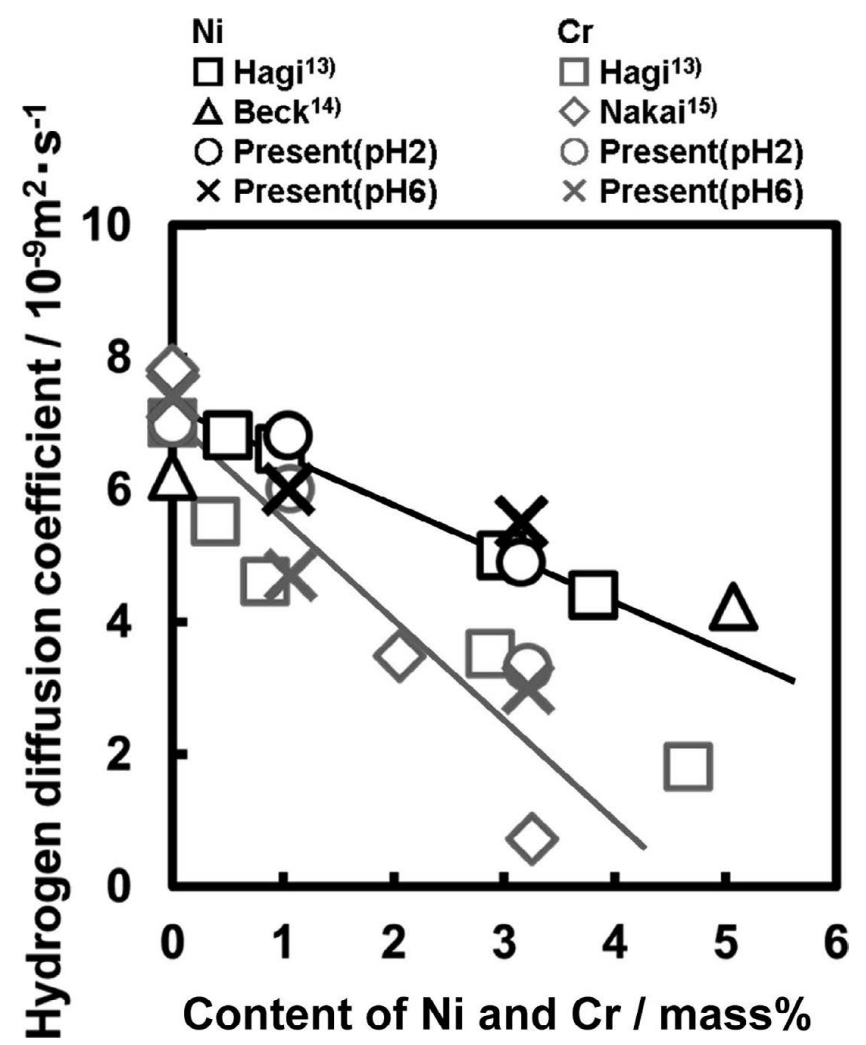

Fig. 2. Effects of a kind and a content of additional elements of $\mathrm{Cr}$ and $\mathrm{Ni}$ on diffusion coefficient of hydrogen. results were shown in Fig. 3. Figures 3(a) and 3(b) were for $\mathrm{Cr}$ - and Ni-added steels, respectively. In addition, gray and black marks indicate for the hydrogen absorption solutions of $\mathrm{pH} 2$ and 6, respectively. In the cathodic potential region, a content of the additional elements of $\mathrm{Cr}$ and $\mathrm{Ni}$ showed almost no effect on the cathodic current density indicating reduction of proton to hydrogen. This fact suggests that the additional elements have no effect on enhancement or suppression of hydrogen generation reaction. The cathodic
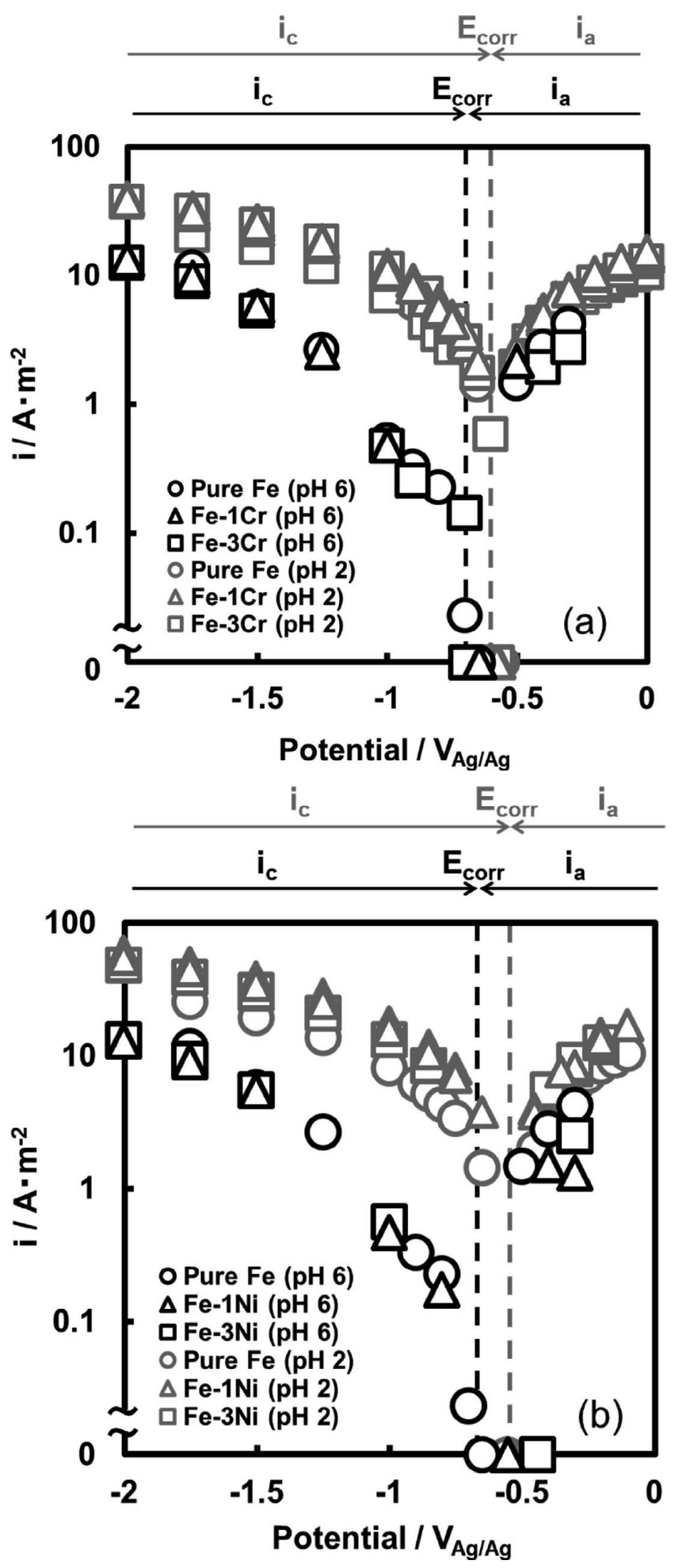

Fig. 3. Polarization curves of the hydrogen absorption surfaces for (a) Cr- and (b) Ni-added steels. 
current density was larger in the solution of $\mathrm{pH} 2$ than that of $\mathrm{pH} 6$ because proton was the main source of the cathodic reaction.

From the same test, correlation between $C_{0}$ and a potential applied to the hydrogen absorption surface was obtained. The results were shown in Fig. 4. Differences between Figs. 4(a) and 4(b) and between gray and black marks in the figures are the same as that for Fig. 3. It is obvious in the figures that a larger $C_{0}$ was obtained when a lower cathodic potential was applied to the specimen surface. Now, the results tested in the solution of $\mathrm{pH} 6$ (black
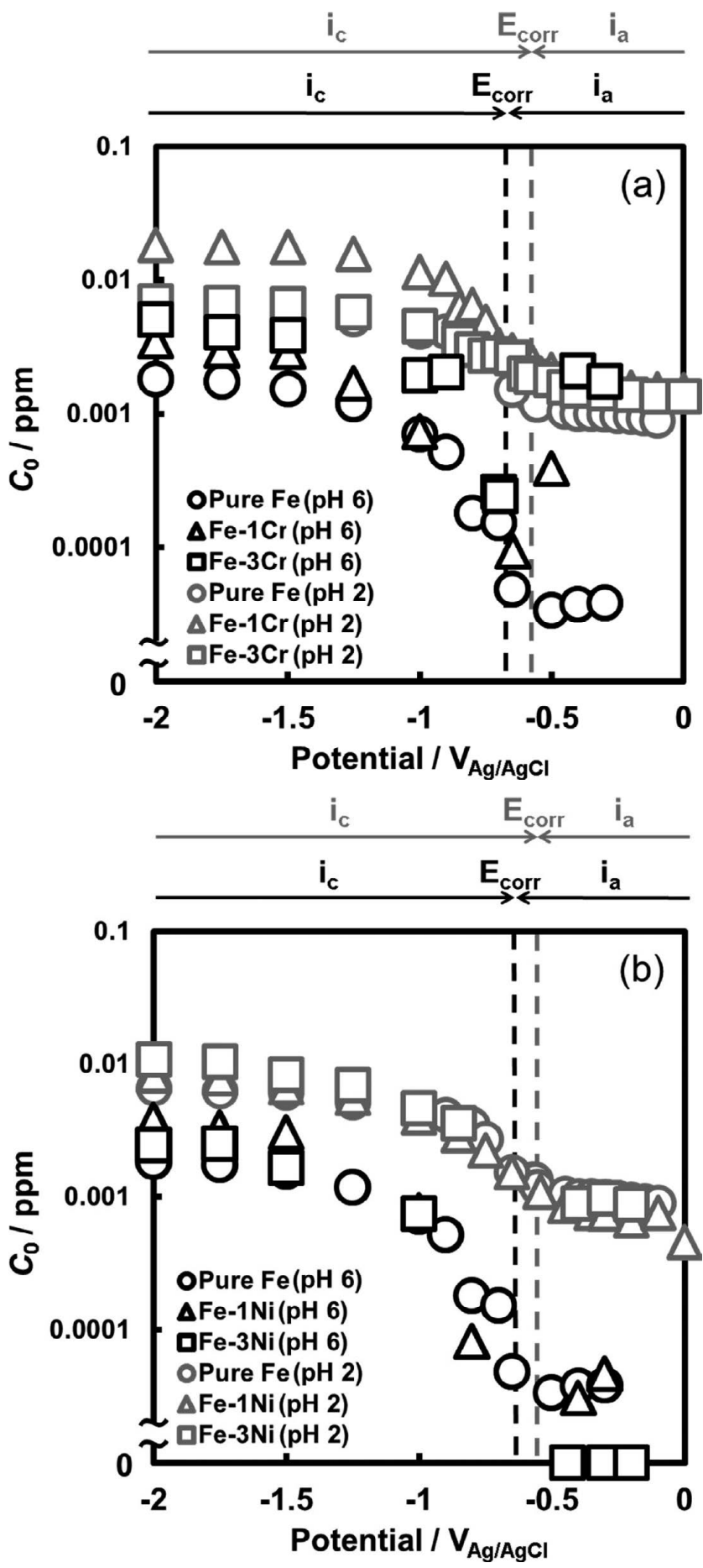

Fig. 4. Effect of applied potential on hydrogen concentration at the hydrogen absorption surface, $C_{0}$, of (a) $\mathrm{Cr}$ - and (b) Niadded steels. marks) were focused. In the cathodic potential region for the Cr-added steel (Fig. 4(a)), $C_{0}$ increased with an increase in a $\mathrm{Cr}$ content. On the other hand, $C_{0}$ seemed to be almost independent of a $\mathrm{Ni}$ content in the cathodic potential region for the Ni-added steel (Fig. 4(b)). The results tested in the solution of $\mathrm{pH} 2$ (gray marks) exhibited almost no remarkable change in $C_{0}$ with the contents of $\mathrm{Cr}$ or $\mathrm{Ni}$.

\subsubsection{Anodic Potential Region}

The polarization curves of the hydrogen absorption surface, as shown Fig. 3, also indicated that anodic current density was almost independent of a kind and a content of the additional element in the anodic potential region. Therefore, active dissolution process of the steels is considered to be independent of a kind and a content of the additional element.

Figure 4 exhibited that $C_{0}$ in the anodic potential region was dependent on a kind of the additional element and solution $\mathrm{pH}$. In the case of $\mathrm{pH} 2, C_{0}$ was smaller when more positive potential was applied to the specimen, but $C_{0}$ was still measured and its decrement became mild in the anodic potential region. The curves of the specimens with different kinds and contents of the additional elements were almost the same each other. In the case of $\mathrm{pH} 6$, however, $C_{0}$ of the $\mathrm{Cr}$-added steel was a larger when more positive potential was applied to the specimen, in spite that the anodic current density was observed in Fig. 3 . In addition, $C_{0}$ achieved the value in the solution of $\mathrm{pH} 2 . C_{0}$ of the Ni-added steel was similar to or less than $\mathrm{Fe}$, and almost independent of the applied anodic potential.

\section{Discussion}

\subsection{Estimation of Hydrogen Absorption Rate}

So far, the chemical process during the hydrogen permeation test including the evolution and the absorption reactions of hydrogen has been considered as below: Proton or water molecular changes to ad-atom of hydrogen on the hydrogen absorption surface at a cathodic potential by discharge reactions;

$$
\begin{array}{r}
\mathrm{H}^{+}+\mathrm{e}^{-} \rightarrow \mathrm{H}_{\mathrm{ad}} \\
\mathrm{H}_{2} \mathrm{O}+\mathrm{e}^{-} \rightarrow \mathrm{H}_{\mathrm{ad}}+\mathrm{OH}^{-}
\end{array}
$$

where $\mathrm{H}_{\mathrm{ad}}$ is ad-atom of hydrogen on the steel surface. There are two reactions to change from the ad-atoms to molecular hydrogens;

$$
\begin{array}{r}
2 \mathrm{H}_{\mathrm{ad}} \rightarrow \mathrm{H}_{2} \\
\mathrm{H}_{\mathrm{ad}}+\mathrm{H}^{+}+\mathrm{e}^{-} \rightarrow \mathrm{H}_{2}
\end{array}
$$

A part of $\mathrm{H}_{\mathrm{ad}}$ absorbs into the steel:

$$
\mathrm{H}_{\mathrm{ad}} \rightarrow \mathrm{H}_{\mathrm{ab}}
$$

where $\mathrm{H}_{\mathrm{ab}}$ is absorbed hydrogen. $\mathrm{H}_{\mathrm{ab}}$ diffuses into inside of the steel based on Fick's second law of Eq. (1), and then the rate at which $\mathrm{H}_{\mathrm{ab}}$ reaches the hydrogen detection surface, i.e., hydrogen permeation rate, is electrochemically measured as a current density.

As mentioned above, the hydrogen permeation test exhibited that the empirical $i_{\mathrm{H}}$ transient was good agreement with 
the theoretical one calculated by Eqs. (1) to (3) of Fick's law with the conditions. The fact strongly indicates that the permeation process always takes place under the boundary condition of Eq. (3), in other words, $C_{0}$ achieves the concentration which is determined by the applied potential and the solution conditions in a relatively short time and sustains during the test. ${ }^{16)}$ In this research, it is desired that a maximum value of the hydrogen absorption rate for Eq. (10) is obtained, and it seems that $i_{\mathrm{H}}(t=\infty)$ represents a hydrogen absorption rate. However, $i_{\mathrm{H}}(t=\infty)$ is not a sufficient index for evaluating hydrogen absorption rate because the initial hydrogen absorption rate is considered to be quite larger than $i_{\mathrm{H}}(t=\infty)$, and $i_{\mathrm{H}}(t=\infty)$ changes with a specimen thickness.

Rapid achievement of $C_{0}$ fixed by the applied potential and the solution conditions in the permeation test are able to presume quasi-equilibrium state of the hydrogen absorptiondesorption reaction for the steel relating to Eq. (10). This quasi-equilibrium state provides that a reaction rate of hydrogen absorption, $v_{\mathrm{ab}}$, is the same as that of hydrogen desorption, $v_{\text {de }}$. In the case that the both rates can express the first order against hydrogen concentration, that is,

$$
\begin{aligned}
& v_{\mathrm{ab}}=k_{+10} \theta_{a d} \\
& v_{\mathrm{de}}=k_{-10} C_{0}
\end{aligned}
$$

where $k_{+10}$ and $k_{-10}$ are forward (absorption) and backward (desorption) reaction for Eq. (10), respectively, and $\theta_{\mathrm{ad}}$ is a fraction of surface coverage by adsorbed hydrogen. Therefore, the quasi-equilibrium state provides the following equation, ${ }^{17}$ )

$$
K=k_{+10} / k_{-10}=C_{0} / \theta_{\mathrm{ad}}
$$

where $K$ is an equilibrium constant for Eq. (10). Equation (13) indicates that a larger $C_{0} / \theta_{\text {ad }}$ leads a larger $k_{+10} / k_{-10}$, meaning acceleration of hydrogen absorption rate or suppression of hydrogen desorption rate.

A cathodic current density on the hydrogen absorption surface, $i_{c}$, defines generally as follows,

$$
i_{\mathrm{c}}=F k_{+6} a_{\mathrm{H}+}\left(1-\theta_{\mathrm{ad}}\right) \exp (-\alpha F \eta / R T)
$$

where $F$ is Faraday's constant, $k_{+6}$ is a reaction rate constant for Eq. (6), $a_{\mathrm{H}+}$ is an activity of proton in the solution, $\alpha$ is a transfer efficient, $\eta$ is an over voltage regarding hydrogen generation reaction, $R$ is a gas constant, and $T$ is a temperature. As already shown in Fig. $3, i_{\mathrm{c}}$ at a given potential in the solution at a given $\mathrm{pH}$ was almost independent of a kind and a content of additional element $(\mathrm{Cr}$ and $\mathrm{Ni}$ ). The fact suggests that $\theta_{\mathrm{ad}}$ is also almost independent of the parameters. On the other hand, $C_{0}$ at a given potential in the solution at a given $\mathrm{pH}$ seemed to be dependent on the parameters as shown in Fig. 4. Since $C_{0}$ is considered to correlate positively with $K$, i.e., a ratio of $v_{\mathrm{ab}}$ to $v_{\text {de }}$, the effect of a kind of additional element on $C_{0}$ was tried to be discuss from the viewpoint of hydrogen absorption rate hereafter.

\subsection{Hydrogen Absorption Rate Depending on Addi- tional Elements of $\mathrm{Cr}$ and $\mathrm{Ni}$}

Iyer et al. analyzed the hydrogen permeation data to derive a relation between $i_{\mathrm{c}}$ and $i_{\mathrm{H}}(t=\infty) .{ }^{18)}$ They assumed the following situations for the hydrogen generation and its absorption. (i) Hydrogen discharge involves only a single electron transfer reaction (Eq. (6)). (ii) An over voltage is sufficient to hydrogen discharge and the recombination step is not rate-determining, so that the backward reaction of Eq. (6) can be neglected. (iii) Langmuir conditions are satisfied for the surface coverage of adsorbed hydrogen. (iv) Hydrogen evolution occurs only by the chemical recombination reaction (Eq. (8)). (v) Intermediate absorption-desorption reaction of Eq. (10) is in local equilibrium state. (vi) Permeation flux, $i_{\mathrm{H}}$, is satisfied by Eqs. (1) to (3). (vii) $i_{\mathrm{c}}$ in steady state is a sum of $i_{\mathrm{H}}(t=\infty)$ and $i_{\mathrm{r}}$, where $i_{\mathrm{r}}$ is the current density corresponding to a rate of hydrogen recombination reaction (Fig. (8)). (viii) The net rate of hydrogen absorption $\left(i_{\mathrm{H}}\right)$ is a difference between absorption rate and desorption rate of hydrogen. From the assumptions, the following formulae were lead in the steady state;

(ii): Eq. (14)

$$
\text { (iv) }: i_{\mathrm{r}}=F k_{+8} \theta_{\mathrm{ad}}^{2}
$$

(vi) : $i_{\mathrm{H}}(t=\infty)=F D C_{0} / L$

$$
\text { (vii) : } i_{\mathrm{c}}=i_{\mathrm{H}}(t=\infty)+i_{\mathrm{r}}
$$

$$
\text { (viii) : } i_{\mathrm{H}}(t=\infty) / \mathrm{F}=v_{\mathrm{ab}}-v_{\mathrm{de}}
$$

Equations (14) to (18) derives the following formulae,

$$
\begin{aligned}
& i_{\mathrm{H}}(t=\infty)=a\left\{b\left(F k_{+8}\right)^{1 / 2}\right\}^{-1} i_{\mathrm{r}}^{1 / 2} \\
& a=k_{+10} /\left(k_{-10}+D / L\right) \\
& b=L /(F D)
\end{aligned}
$$

In most of the permeation test with a relatively large $i_{\mathrm{c}}$, $i_{\mathrm{H}}(t=\infty)$ is quite smaller than $i_{\mathrm{c}}$, then $i_{\mathrm{r}}$ is nearly equal to $i_{\mathrm{c}}$. The conditions change Eq. (19) into the following equation,

$$
i_{\mathrm{H}}(t=\infty)=a\left\{b\left(F k_{+8}\right)^{1 / 2}\right\}^{-1} i_{\mathrm{c}}^{1 / 2}
$$

Equation (20) indicates $i_{\mathrm{H}}(t=\infty)$ is a proportional of $i_{\mathrm{c}}{ }^{1 / 2}$. The relation between the two parameters was confirmed by several reports. ${ }^{17,19-21)}$ Here, the present permeation data was analyzed to confirm the relation between $i_{\mathrm{H}}(t=\infty)$ and $i_{\mathrm{c}}{ }^{1 / 2}$, and $i_{\mathrm{H}}(t=\infty)$ was changed into $C_{0}$ by Eq. (5). The results were shown in Fig. 5 for employing the solution of $\mathrm{pH}$ 6, for instance. In these figures, all of the permeation data (not average value) were plotted. It is clear in these figures that the data were almost linearly lined up in the current density range more than $1 \mathrm{~A} \cdot \mathrm{m}^{-2}$. The facts suggest that the present hydrogen permeation data are satisfied with the assumptions as mentioned above. In addition, the permeation data obtained in the solution of $\mathrm{pH} 2$ exhibited the same linear relationship between them. Figure 5 also informed that the slope of the line is dependent on a kind and a content of additional element. Therefore, the correlation between the slope and the content of the additional element was confirmed as shown in Fig. 6. The figure remarkably exhibited that the slope increased with an increase in the content of the additional elements of $\mathrm{Cr}$ and $\mathrm{Ni}$, and the increment of the slope was greater for Cr-added steel in both solutions of pHs 2 and 6. The increase in the slope means enhancement of increment for $C_{0}$ corresponding to $K$, i.e., a ratio of $v_{\mathrm{ab}}$ 

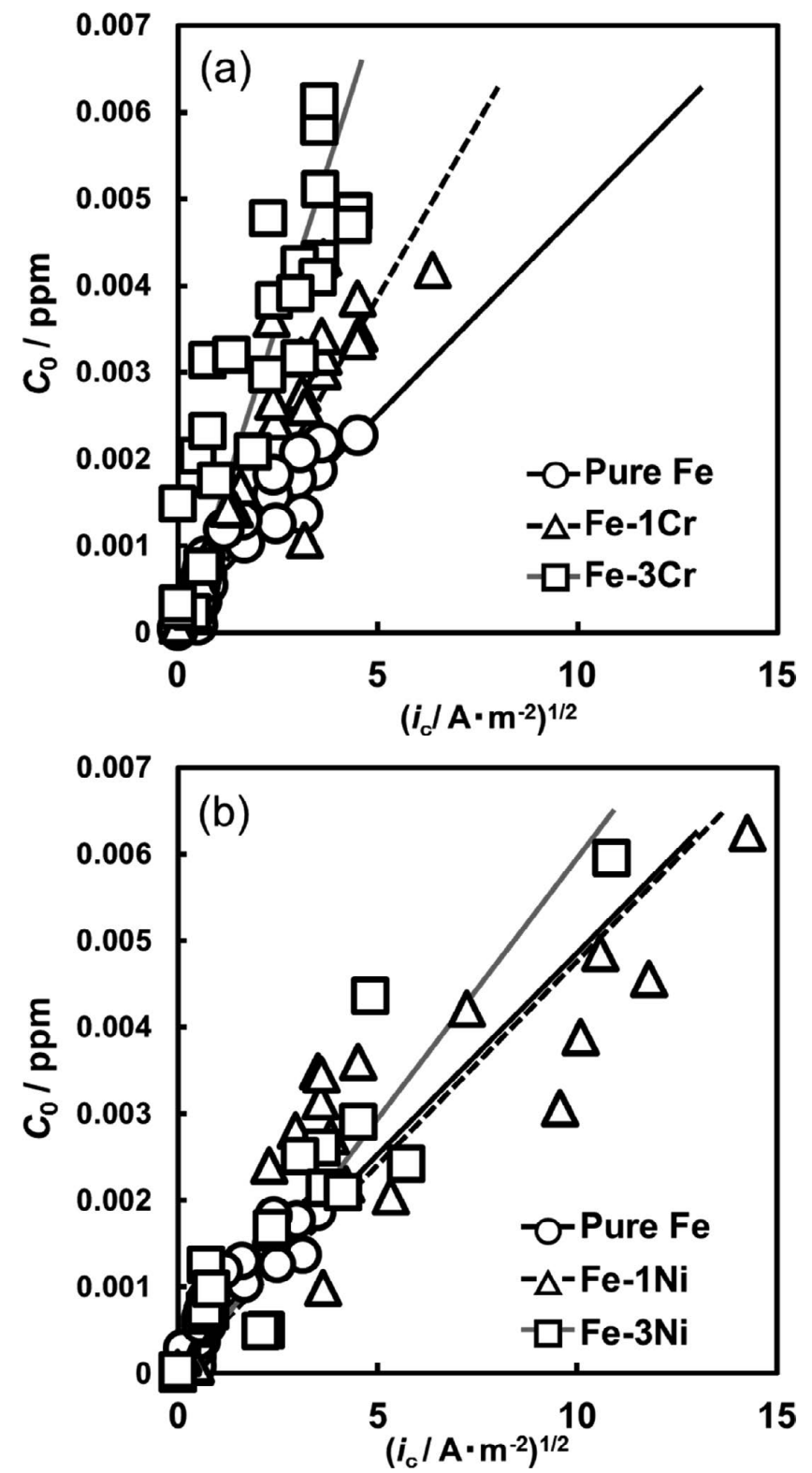

Fig. 5. Correlation between $C_{0}$ and a square root of cathodic current density, $i_{\mathrm{c}}$, of (a) $\mathrm{Cr}$ - and (b) Ni-added steels tested in the solution of $\mathrm{pH} 6$.

to $v_{\text {de. }}$, with a content of the additional elements. Therefore, the facts suggest that absorption rate increases and/or desorption rate decreases with an increase in the content of additional elements of $\mathrm{Cr}$ and $\mathrm{Ni}$, and that $\mathrm{Cr}$ enhances the trends much more.

The behavior of absorption-desorption of hydrogen depending on a kind and a content of the additional elements seems to be opposite to that of diffusion coefficient, $D$, as shown in Fig. 2. The figure indicated that $D$ decreased with an increase in the content of additional element, and $\mathrm{Cr}$ enhanced a decrement of $D$ much more than Ni. It is known that most of additional elements in solid-solution state in the steel act as sites of trap for hydrogen in the steel to be obstacles for hydrogen diffusion. Therefore the fact may inform that $\mathrm{Cr}$ attracts and traps hydrogen. The feature of $\mathrm{Cr}$ and $\mathrm{Ni}$ for attracting hydrogen may be applicable to the hydrogen absorption process, that is, $\mathrm{Cr}$ and $\mathrm{Ni}$ existing on the hydrogen absorption surface attract adsorbed hydrogen

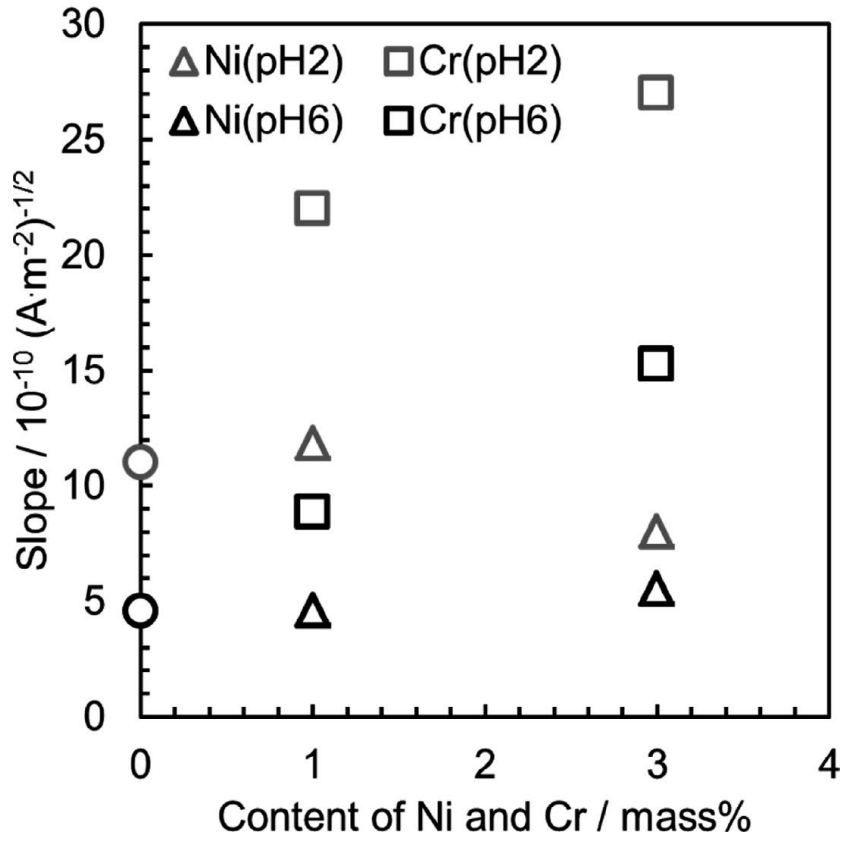

Fig. 6. Correlation between the content of the additional elements and the slope of the linear line shown in Fig. 5.

around themselves, fix it for a while, and then make hydrogen absorbing. In other words, the additional elements of $\mathrm{Cr}$ and $\mathrm{Ni}$ may enhance hydrogen absorption rate. Moreover, $\mathrm{Cr}$ may be much more attractive to adsorbed hydrogen to enhance hydrogen absorption rate than Ni. The feature of the additional element can explain the permeation behavior in the steady state as shown in Fig. 6.

\section{3. $C_{0}$ of the Specimen in Anodic Potential Region}

As mentioned in Fig. 4, $C_{0}$ of Fe was smaller when more positive potential was applied to the specimen in the solution of $\mathrm{pH} 2$ in whole the potential region. In addition, the decrease in $C_{0}$ was more rapid in the cathodic and milder in the anodic region when the applied potential was more positive. The trend of decrease in $C_{0}$ (corresponding to $i_{\mathrm{H}}(t=\infty)$ ) was also observed in the other researches. ${ }^{22)}$ Both the $\mathrm{Cr}$ - and $\mathrm{Ni}$-added steels showed a quite similar value of $C_{0}$ to Fe in anodic potential region in the solution of $\mathrm{pH} 2$. In the case of $\mathrm{pH} 6$, on the other hand, $C_{0}$ obtained in the anodic potential region was different between the $\mathrm{Cr}$ - and the Ni-added steels, that is, $C_{0}$ of the Cr-added steel was larger and that of the Ni-added steel was smaller than that of Fe. This difference was not observed in the solution of $\mathrm{pH} 2$. It is considered that the effect of $\mathrm{Cr}$ on the enhancement of hydrogen absorption is resulted from the trap effect to hydrogen at the surface as described before and acidified ability of dissolved $\mathrm{Cr}^{3+}$ by hydrolysis. The effect of $\mathrm{Ni}$ on the suppression of hydrogen absorption and of susceptibility of HE for the high strength steels was recognized. ${ }^{23)}$ The reason of the effect of $\mathrm{Ni}$ is now investigating.

\section{Conclusions}

Effect of additional elements of $\mathrm{Cr}$ and $\mathrm{Ni}$ in iron on hydrogen absorption behavior has been investigated by polytetrafluoroethylene conventional electrochemical hydrogen permeation test. The results were summarized as 
follows.

- A diffusion coefficient decreased with an increase in a content of additional elements of $\mathrm{Cr}$ and $\mathrm{Ni}$, and the decrement was enhanced much more by $\mathrm{Cr}$ than by Ni.

- Quasi-equilibrium state to the absorption-desorption reactions of hydrogen at the hydrogen absorption surface was presumed at any permeation period, and then correlation between hydrogen absorption rate and concentration of hydrogen at the hydrogen absorption surface, $C_{0}$, was pointed out.

- $C_{0}$ was almost proportional to a square root of the cathodic current density at the hydrogen absorption surface for any specimens. The slope increased with an increase in the content of the additional elements, and the increment was enhanced much more by $\mathrm{Cr}$ than by $\mathrm{Ni}$.

- The additional elements of $\mathrm{Cr}$ and $\mathrm{Ni}$ were suggested to attract hydrogen, and the effect leads hydrogen ad-atom absorbing into the iron specimen. In addition, the attraction effect of $\mathrm{Cr}$ was much more than that of $\mathrm{Ni}$.

- Under anodic potential region, the effect of additional element on $C_{0}$ was not clearly obtained in the solution of $\mathrm{pH}$ 2 , but it was found that $C_{0}$ of the $\mathrm{Cr}$-added steel was larger and that of the Ni-added steel was smaller than that of $\mathrm{Fe}$ in the solution of $\mathrm{pH} 6$.

\section{Acknowledgements}

One of the authors thanks the study group, "Comprehensive Understanding of Hydrogen-Passive Surface on Steels for Prevention of Hydrogen Embrittlement" in Iron and Steel Institute of Japan for sufficient discussion to our research results and a part of financial support. In addition, the authors thank Dr. A. Tahara, National Institute of Materials Science, for providing the specimens.

\section{REFERENCES}

1) S. Matsuyama: Tetsu-to-Hagané, 80 (1994), 679.

2) Fundamental Aspect of Stress Corrosion Cracking, National Association of Corrosion Engineers, Houston, TX, (1961).

3) Stress Corrosion Cracking and Hydrogen Embrittlement of Iron Base Alloys, National Association of Corrosion Engineers, Houston, TX, (1977).

4) M. Nagumo: Suisozeika no Kiso, Uchida Rokakuho, Tokyo, (2008).

5) T. Omura: ISIJ Int., 52 (2012), 267.

6) T. Omura, T. Kushida, T. Kudo, F. Nakasato and S. Watanabe: Zairyo-to-Kankyo, 54 (2005), 61.

7) Proc. Symp. on Comprehensive Understanding of Hydrogen-Passive Surface on Steels for Prevention of Hydrogen Embrittlement, Part-1, ISIJ, Tokyo, (2013).

8) Proc. Symp. on Comprehensive Understanding of Hydrogen-Passive Surface on Steels for Prevention of Hydrogen Embrittlement, Part-2, ISIJ, Tokyo, (2013)

9) Proc. Symp. on Comprehensive Understanding of Hydrogen-Passive Surface on Steels for Prevention of Hydrogen Embrittlement, Part-3, ISIJ, Tokyo, (2014).

10) Proc. Symp. on Comprehensive Understanding of Hydrogen-Passive Surface on Steels for Prevention of Hydrogen Embrittlement, Part-4, ISIJ, Tokyo, (2014).

11) S. Yoshizawa, T. Tsuruta and K. Yamakawa: Corros. Eng. (Jpn.), 24 (1975), 511.

12) M. A. V. Devanathan and Z. Stachurski: Proc. Roy. Soc. Lond. A, A270 (1962), 90

13) H. Hagi, Y. Hayashi and N. Ohtani: J. Jpn. Inst. Met., 45 (1981), 276.

14) W. Beck, J. O. M. Bockris, M. A. Genshaw and P. K. Subramanyan: Metall. Trans., 2 (1971), 883.

15) Y. Nakai, Y. Uesugi and H. Shimanaka: Kawasaki Steel Giho, 6 (1974), 324.

16) T. Hara: Zairyo-to-Kankyo, 60 (2011), 259.

17) J. O’M. Bockris, J. McBreen and L. Nanis: J. Electrochem. Soc., 112 (1965), 1025.

18) R. N. Iyer, H. W. Pickering and M. Zamanzadeh: J. Electrochem. Soc., 136 (1989), 2463.

19) C. Kato, H. J. Grabke, B. Egert and G. Panzner: Corros. Sci., 24 (1984), 591.

20) M. Zamanzadeh, A. Allam, H. W. Pickering and G. K. Hubler: $J$. Electrochem. Soc., 127 (1980), 1688.

21) R. M. Latanision and M. Kurkela: Corrosion, 39 (1983), 174.

22) S. Yoshizawa, T. Tsuruta and K. Yamakawa: Corros. Eng. (Jpn.), 25 (1976), 77.

23) T. Shiraga, N. Ishikawa, M. Ishiguro, E. Yamashita and S. Mizoguchi: Tetsu-to-Hagané, 82 (1996), 777. 